\title{
Knowledge of Polycystic Ovarian Syndrome, Its Complications, and Management among Lebanese Women: A Cross-Sectional Survey
}

\author{
Farah Al Souheil ${ }^{1} \quad$ Bahia Chahine ${ }^{1}$ \\ ${ }^{1}$ Biomedical Sciences Department, School of Pharmacy, Lebanese \\ International University, Beirut, Lebanon \\ J Health Allied Sci ${ }^{\mathrm{NU}}$ 2022;12:267-273.
}

\begin{abstract}
Address for correspondence Bahia Chahine, PharmD, MSc, BCPS, School of Pharmacy, Lebanese International University, Beirut, Lebanon (e-mail: bahia.chahine@liu.edu.lb).
\end{abstract}

\begin{abstract}
Introduction Polycystic ovarian syndrome (PCOS) is a multi-spectrum disease where a failure to address it correctly can result in various clinical complications. This study aimed to assess the Lebanese women's knowledge and perceptions of PCOS and its management.

Materials and Methods This cross-sectional study included women whose ages ranged between 18 and 45 years. Women's demographic characteristics, reproductive health, knowledge, and perception of PCOS were analyzed through an online validated questionnaire. Results Among the 450 included women, 196 (43.6\%) had good knowledge about PCOS. The majority of participants were aware that menstrual irregularity is a symptom of PCOS, 327 (72.7\%), while only 231 (51.3\%) women knew that PCOS may lead to

Keywords

- polycystic ovary syndrome

- health knowledge, attitudes, practice

- female

- Lebanon infertility. Almost two-thirds of women were aware of the contribution of metformin, diet, and exercise in refining the progress of the disease. More than $60 \%$ of participants believed that PCOS patients need social support and have a low body image. Married women $(p<0.001)$ and those with undergraduate/ postgraduate degrees $(p<0.001)$ had better PCOS knowledge.

Conclusion A significant percentage of Lebanese women have inadequate knowledge of PCOS and its complications.
\end{abstract}

\section{Introduction}

Polycystic ovarian syndrome (PCOS) is the most common metabolic and endocrine disorder known to affect women of reproductive age, with a prevalence ranging from $6 \%$ to $20 \%{ }^{1}$

PCOS can be diagnosed by one of the following accepted diagnostic criteria: Rotterdam, National Institute of Health, and Androgen Excess PCOS Society, where a minimum of 10 cysts of 2 to $8 \mathrm{~mm}$ diameter is often present on the ultrasound of one or both ovaries. ${ }^{2}$ Ovarian volume is usually increased in at least one ovary by more than $10 \mathrm{~mL}^{2}$ Notably, presenting symptoms among adult women tend to be heterogeneous, making it a diagnostic challenge. ${ }^{2}$ Additionally, underdiagnosis may be prominent due to a possible lack of knowledge and awareness among women.

Generally, menstrual irregularities, hirsutism, infertility, miscarriage, or accompanying metabolic disorders (e.g., obesity, dyslipidemia, or insulin resistance) lead to adventitious clinical visits that elicit diagnosis. In this sense, more than half of women with PCOS report to the physician for infertility problems, and the third quarter of them complain chiefly of published online December 1, 2021
DOI https://doi.org/ $10.1055 / \mathrm{s}-0041-1740025$. ISSN 2582-4287.

\footnotetext{
(C) 2021. Nitte (Deemed to be University). All rights reserved. This is an open access article published by Thieme under the terms of the Creative Commons Attribution-NonDerivative-NonCommercial-License, permitting copying and reproduction so long as the original work is given appropriate credit. Contents may not be used for commercial purposes, or adapted, remixed, transformed or built upon. (https://creativecommons.org/ licenses/by-nc-nd/4.0/)

Thieme Medical and Scientific Publishers Pvt. Ltd., A-12, 2nd Floor, Sector 2, Noida-201301 UP, India
} 
oligomenorrhea or amenorrhea. ${ }^{3}$ Therefore, clinical features may differ broadly depending on which of the four phenotypes, suggested by Rotterdam, the patient is presenting with. ${ }^{4}$

Many hypotheses have been suggested to understand better the pathophysiology of PCOS; however, little is known about its precise etiology. ${ }^{5,6}$ It is also claimed that PCOS may be heritable with PCOS-susceptibility loci and leptin receptor gene being suggested as possible genetic attributes. ${ }^{7,8}$

PCOS therapy is largely limited to symptomatic management of posed complications and lifestyle modifications. Strikingly, dietary restrictions and physical exercise can restore normal hormone levels, reduce cyst size, induce ovulation, and mitigate disturbing symptoms. ${ }^{9}$

Overall, the reproductive and metabolic complications suffered by women with PCOS impose a heavy financial burden. ${ }^{10,11}$ By comparing women with PCOS to healthy volunteers, Hart et al have found in their study that PCOS are twice more likely to be admitted to hospital. ${ }^{12}$ Effects may also extend beyond physiologic complications, where PCOS patients are 3.8 times more likely to suffer from depression. ${ }^{13}$ Patients may also suffer from anxiety and a poor quality of life. ${ }^{13}$

A study conducted by Patel et al reported that only $40 \%$ of Indian women were aware of PCOS. ${ }^{14}$ Another study assessing the prevalence and awareness of female university students in Pakistan reported an increased incidence of PCOS but limited awareness. ${ }^{15}$ Similar reports were obtained from other countries in the middle east (Saudi Arabia and Jordan) where limited awareness was found among women. ${ }^{16,17}$ More importantly, research suggests that many women with PCOS tend to search the internet for information rather than consulting with a healthcare professional due to a possible hesitation to talk about reproductive issues. ${ }^{18}$ This condition may lead to a discrepancy in the level of patients' knowledge-accuracy, underdiagnosis, and significant disease complications.

Given the importance of this topic, much effort has been dedicated to research in Lebanon to address this complex problem; however, none of the latter has tackled the prevalence and public awareness of this syndrome. It is therefore not clear if Lebanese women are aware of PCOS and its complications. Thereby, this study sought to evaluate the Lebanese women's knowledge of PCOS and its management.

\section{Materials and Methods}

\section{Study Design and Questionnaire Development}

This cross-sectional observational study analyzed Lebanese women's knowledge and perception of PCOS. Adult women of reproductive age (18-45 years) were included in the study, except for those refusing to sign up for the electronic consent; thus, participation was voluntary and anonymous. This study was reviewed and approved by the Institutional Review Board of the Lebanese International University, School of PharmacyBeirut. Data were collected from January until June 2020.

The research was conducted using a questionnaire that was adapted from previous similar studies on PCOS. ${ }^{17,19} \mathrm{After}$ drafting the questionnaire, it was examined by five expert academics and five women for the face and content validity. Based on their feedback, several changes were made to the language of questions to improve clarity, and several statements were adjusted to ensure that all items were comprehended. The final questionnaire was written in English and then translated into Arabic. Following the completion of the translation, the questionnaire was back-translated from Arabic to English to ensure consistency. The questionnaire was later available online in a Google form, and the survey link was randomly circulated online through the different social media platforms (i.e., Facebook and Whatsapp) for a duration of 8 weeks.

On the first page of the questionnaire, the study's objective was explained to the participants, and they were assured that the information they provide will be kept confidential and anonymous. The questionnaire included 41 items and was organized into three sections. The first section covered the sociodemographic characteristics including the smoking status that was labeled per the CDC definitions: Current smokers included adults who have smoked 100 cigarettes in their lifetime and who currently smoke, ex-smokers included former smokers who have smoked 100 cigarettes in their lifetime but are not currently smoking, while non-smokers included persons who have had less than 100 cigarettes in their lifetime or have never smoked. ${ }^{20}$ In the second section, participants were asked 24 questions to assess their knowledge about the physiology of the female reproductive system, the pathophysiology, complications, and management of PCOS. Knowledge score was calculated by summing the number of correct answers. Scores ranged from 0 to 24, with $0-9$ : inadequate knowledge, 10-17: satisfactory, 18-24: good knowledge. In the last section, women also answered to what extent they agree with the seven variables related to PCOS to assess their perception of the disorder.

The calculated minimum sample needed sample was 343 based on an estimated prevalence of PCOS knowledge of 50\% in the Lebanese reproductive-aged female population as there are no previous similar studies conducted in Lebanon. The calculations assumed a confidence level of $95 \%$, a margin of error of $5 \%$ using the Epi info sample size calculator.

\section{Statistical Analysis}

Data analysis was performed using SPSS (Statistical Package for Social Sciences) version 25.0 (IBM SPSS Inc., Armonk, NY, USA). Mean and standard deviation were used to describe continuous variables, while percentages were used for qualitative variables. Factors significantly associated with PCOS knowledge in the simple regression were included in the multiple linear regression model. The logistic regression analysis was adjusted for age, marital status, educational level, employment status, physical activity, use of contraceptives, and history of infertility. A $p$-value below or equal to 0.05 was considered significant for all analyses.

\section{Results}

Four hundred fifty questionnaires were wholly filled and analyzed. The demographic characteristics of participants 
are presented in - Table 1. The mean age of participating women was 29.8 years \pm 12.2 . In this study, 324 (72\%) participants were single, with 259 (57.6\%) women attending and $98(21.8 \%)$ others had attended college. The majority of women, 299 (64.4\%) were not working, 325 (72.2\%) were non-smokers, and 341 (75.8\%) were free of chronic diseases. Comparable percentages of participants engaged in variable levels of activity: 150 (33.3\%) seldom practiced, 157 (34.9\%) occasionally, and 143 (31.8\%) did that often.

When surveying the females' reproductive health, 306 (68\%) reported non-use of oral contraceptives, 294 (65.3\%) had a cycle length within the average interval (25-34). In comparison, a total of $72(16 \%)$ married women had a history of infertility.

Participants' understanding of the different PCOS aspects is illustrated in - Table $\mathbf{2}$. Women had a relatively decreased level of knowledge of the reproductive system's physiology. However, women reported the best knowledge in this section of the cysts' definition, where 290 (64.4\%) women knew that cysts are follicles with a single egg inside. A comparable percentage of women did not know that ovulation is essential for fertility, progesterone released after ovulation is responsible for uterine shedding, and that this shedding is a protective factor against uterine cancer. Interestingly, more than half of the participating women failed to recognize that the amount of free testosterone is affected by body fat and insulin (237 [52.7\%] and 297 [66\%], respectively).

Participants in this study demonstrated a better degree of recognition of the pathophysiology of PCOS. Around 70\% of participants perceived that a polycystic ovary has more follicles than a regular one and 273 (60.7\%) of them knew that these ovaries tend to ovulate less than the average. Irregularity or absence of menses was recognized as a symptom of PCOS by 325 (72.2\%) participants compared with 254 (56.4\%) women being aware that testosterone level production is increased and other 341 (75.8\%) knowing that these elevated levels may result in undesired features (e.g., acne, alopecia, and hirsutism). In addition, 302 (67.1\%) women realized that high insulin levels are expected in women with PCOS. The majority of participants were also aware of the diagnostic tools-ultrasound recognized by 299 (66.4\%) women, and specific blood tests known to 303 (67.3\%) of participants.

Women participating in this study had substantially poor knowledge of PCOS complications. Around half of the participants knew that PCOS might result in infertility. Similarly, 247 (54.9\%) women were aware of the fact that increased insulin levels increase the risk of diabetes. However, fewer people, 185 (41.1\%), knew that PCOS might cause metabolic syndrome which is a group of symptoms that result in increased risk for diabetes and CVD, a definition only perceived by some, 182 (40.4\%).

Almost all participants, 384 (85.3\%), knew that diet and exercise greatly help PCOS complications by decreasing insulin levels, a mechanism known to nearly two-thirds of the participants, 332 (73.8\%). A similar proportion of women also knew that medications could also lower insulin. Around half of the women knew that by reducing insulin, free
Table 1 Demographic characteristics of the studied women $(N=450)$

\begin{tabular}{|c|c|}
\hline Characteristic & Number (\%) \\
\hline \multicolumn{2}{|l|}{ Age $(y)$} \\
\hline $18-24$ & $229(50.9)$ \\
\hline $25-35$ & $82(18.2)$ \\
\hline$\geq 36$ & $139(30.9)$ \\
\hline Mean (SD) & $29.8(12.2)$ \\
\hline \multicolumn{2}{|l|}{ Marital status } \\
\hline Single & $324(72.0)$ \\
\hline Married & $79(17.6)$ \\
\hline Divorced & $47(10.4)$ \\
\hline \multicolumn{2}{|l|}{ Educational level } \\
\hline Secondary education & $93(20.7)$ \\
\hline Undergraduate education & $259(57.6)$ \\
\hline Postgraduate education & $98(21.8)$ \\
\hline \multicolumn{2}{|l|}{ Employment status } \\
\hline Not working & $290(64.4)$ \\
\hline Working full-time & $110(24.4)$ \\
\hline Working part-time & $50(11.1)$ \\
\hline \multicolumn{2}{|l|}{ Physical activity } \\
\hline Seldom & $150(33.3)$ \\
\hline Occasionally & $157(34.9)$ \\
\hline Often & $143(31.8)$ \\
\hline \multicolumn{2}{|l|}{ Smoking status } \\
\hline Non-smoker & $327(72.7)$ \\
\hline Current smoker & $100(22.2)$ \\
\hline Ex-smoker & $23(5.1)$ \\
\hline \multicolumn{2}{|c|}{ Having chronic medical conditions } \\
\hline Yes & $109(24.2)$ \\
\hline No & $341(75.8)$ \\
\hline \multicolumn{2}{|c|}{ Interval between menstruation (days) } \\
\hline$<25$ days & $40(8.9)$ \\
\hline $25-34$ days & $294(65.3)$ \\
\hline $35-60$ days & $94(20.9)$ \\
\hline Totally variable & $22(4.9)$ \\
\hline \multicolumn{2}{|l|}{ Having a history of infertility } \\
\hline Yes & $72(16.0)$ \\
\hline No & $378(84.0)$ \\
\hline \multicolumn{2}{|l|}{ Using oral contraceptives } \\
\hline Yes & $144(32.0)$ \\
\hline No & $306(68.0)$ \\
\hline
\end{tabular}

testosterone could be decreased, and ovulation can be promoted. Similarly, 240 (53.3\%) participants were aware that decreased testosterone results in reduced hirsutism, acne, and alopecia. 


\begin{tabular}{|c|c|c|c|c|c|c|c|c|c|c|c|c|c|c|c|c|c|c|c|c|c|c|c|c|}
\hline 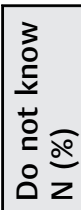 & 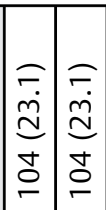 & 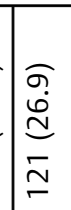 & 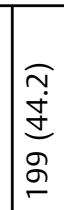 & 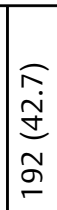 & 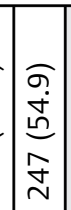 & 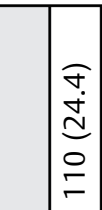 & $\mid \begin{array}{c}\widetilde{N} \\
\tilde{n} \\
\\
\tilde{I}\end{array}$ & $\begin{array}{l}o \\
\dot{0} \\
\stackrel{d}{d} \\
0 \\
0\end{array}$ & $\begin{array}{l}\sigma \\
\dot{0} \\
0 \\
0 \\
\infty \\
\stackrel{0}{-}\end{array}$ & 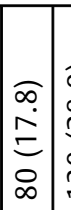 & 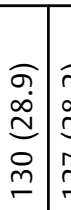 & 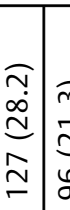 & 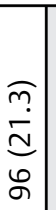 & 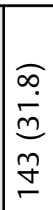 & 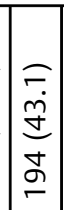 & 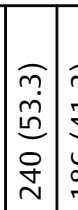 & 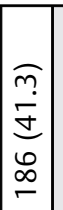 & $\begin{array}{l}\widehat{\partial} \\
\dot{\dot{m}} \\
\underline{m} \\
\underline{m} \\
\end{array}$ & 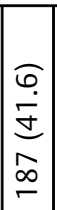 & 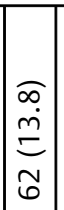 & $\begin{array}{l}\widehat{̃} \\
\stackrel{b}{0} \\
\\
\end{array}$ & 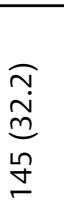 & 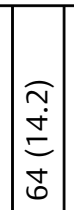 & \\
\hline 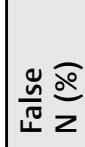 & 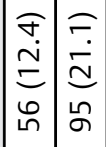 & 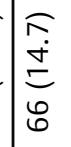 & 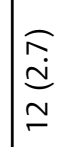 & 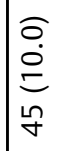 & 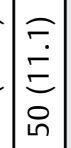 & 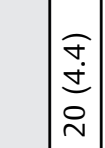 & $\mid \begin{array}{l}\tilde{I} \\
\bar{\Sigma} \\
\tilde{m}\end{array}$ & $\begin{array}{c}\widehat{m} \\
\stackrel{c}{c} \\
m \\
m\end{array}$ & 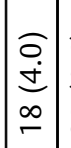 & 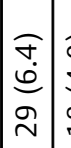 & 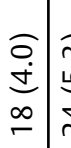 & 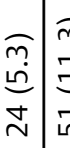 & $\begin{array}{l}\tilde{n} \\
\tilde{E} \\
\bar{E} \\
\text { เn }\end{array}$ & $\begin{array}{l}\tilde{n} \\
\tilde{m} \\
\underline{\Xi} \\
0 \\
0\end{array}$ & 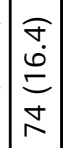 & $\mid \begin{array}{l}0 \\
\omega \\
\stackrel{0}{n} \\
\stackrel{n}{n}\end{array}$ & $\begin{array}{l}\widehat{n} \\
\stackrel{n}{=} \\
m \\
m\end{array}$ & 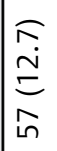 & $\begin{array}{c}\widehat{N} \\
\omega \\
\infty \\
\stackrel{N}{N}\end{array}$ & 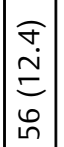 & 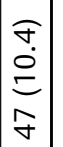 & 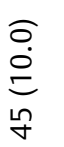 & 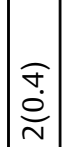 & \\
\hline & 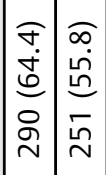 & $\begin{array}{l}\underset{\sigma}{\sigma} \\
\infty \\
\stackrel{\infty}{\omega n} \\
\hat{n} \\
\end{array}$ & $\begin{array}{l}\hat{\bar{n}} \\
\hat{N} \\
\tilde{D} \\
\tilde{N}\end{array}$ & $\begin{array}{l}\frac{\tilde{m}}{\mathfrak{j}} \\
\frac{\dot{y}}{m} \\
\frac{m}{n}\end{array}$ & 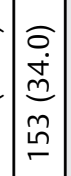 & 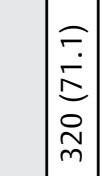 & 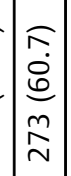 & $\begin{array}{l}\tilde{N} \\
\hat{N} \\
\Sigma \\
\Sigma \\
\tilde{n}\end{array}$ & 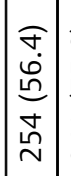 & 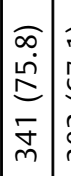 & 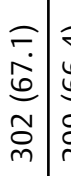 & 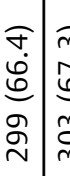 & $\begin{array}{l}\tilde{n} \\
\hat{e} \\
\hat{m} \\
\hat{\infty} \\
m\end{array}$ & 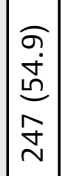 & 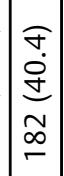 & 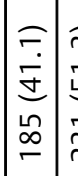 & 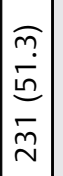 & 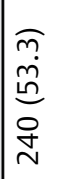 & $\begin{array}{l}\widehat{̃} \\
\tilde{N} \\
\tilde{n} \\
\tilde{\omega} \\
\tilde{N}\end{array}$ & 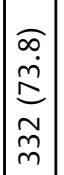 & $\begin{array}{c}\tilde{m} \\
m \\
\\
o \\
m \\
m\end{array}$ & 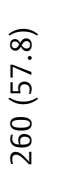 & $\begin{array}{l}\tilde{m} \\
\dot{\infty} \\
\infty \\
\infty \\
\infty \\
m \\
m\end{array}$ & 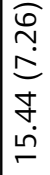 \\
\hline
\end{tabular}

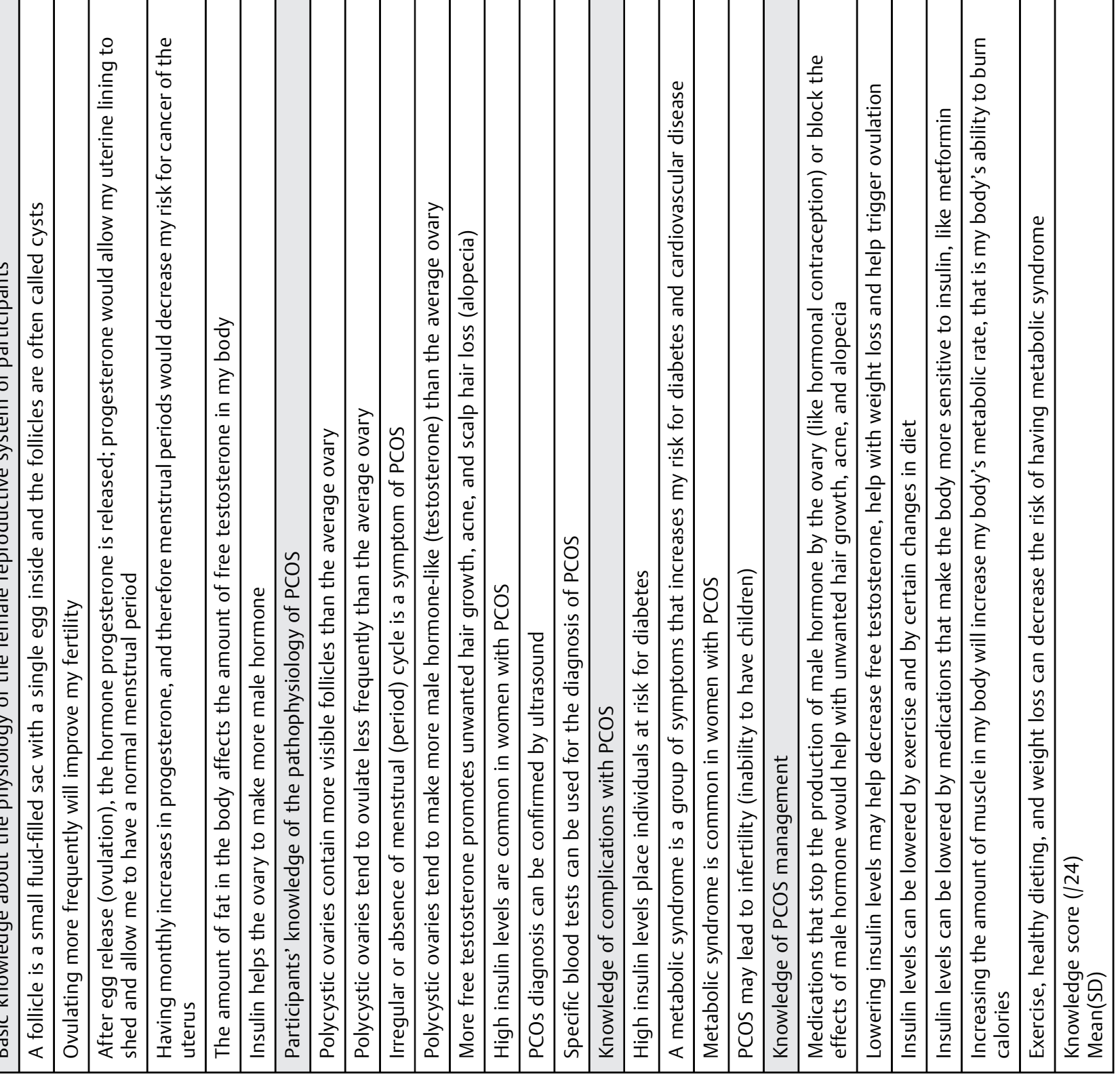


Table 3 Study participants' perception of PCOS

\begin{tabular}{|l|l|l|l|l|l|}
\hline Parameter & $\begin{array}{l}\text { Strongly } \\
\text { disagree } \\
\text { N (\%) }\end{array}$ & $\begin{array}{l}\text { Disagree } \\
\text { N (\%) }\end{array}$ & $\begin{array}{l}\text { Agree } \\
\text { N (\%) }\end{array}$ & $\begin{array}{l}\text { Strongly } \\
\text { agree } \\
\text { N (\%) }\end{array}$ & $\begin{array}{l}\text { Mean (SD) } \\
136(30.2)\end{array}$ \\
\hline $\begin{array}{l}\text { The name PCOS is confusing and gives no clue } \\
\text { about the disease }\end{array}$ & $48(10.7)$ & $114(25.3)$ & $152(33.8)$ & $10.98)$ \\
\hline $\begin{array}{l}\text { PCOS is a permanent condition and cannot be } \\
\text { cured }\end{array}$ & $40(8.9)$ & $170(37.8)$ & $127(28.2)$ & $113(25.1)$ & $2.7(0.94)$ \\
\hline $\begin{array}{l}\text { PCOS cannot be managed through diet and } \\
\text { exercise }\end{array}$ & $48(10.7)$ & $156(34.7)$ & $141(31.3)$ & $105(23.3)$ & $2.67(0.95)$ \\
\hline PCOS patients have low body image & $12(2.7)$ & $162(36.0)$ & $179(39.8)$ & $97(21.6)$ & $2.8(0.80)$ \\
\hline PCOS patients require support social support & $31(6.9)$ & $78(17.3)$ & $200(44.4)$ & $141(31.3)$ & $3.0(0.87)$ \\
\hline $\begin{array}{l}\text { PCOS patients cannot have children (women's } \\
\text { fertility) }\end{array}$ & $61(13.6)$ & $152(33.8)$ & $167(37.1)$ & $70(15.6)$ & $2.55(0.91)$ \\
\hline $\begin{array}{l}\text { Hirsutism due to PCOS can decrease social } \\
\text { performance }\end{array}$ & $29(6.4)$ & $151(33.6)$ & $158(35.1)$ & $112(24.9)$ & $2.78(0.89)$ \\
\hline
\end{tabular}

Strongly disagree $=1$, disagree $=2$, agree $=3$, strongly agree $=4$.

Participants had no dominant perception of PCOS, as observed in - Table 3. However, a slightly increased percentage of women believed that PCOS patients require social support $(3 \pm 0.87)$, the term PCOS may be confusing and not define the disease $(2.84 \pm 0.98)$, and that patients might have a low body image $(2.8 \pm 0.8)$.

Multiple linear regression was performed to assess the possible factors that shape Lebanese women's knowledge of PCOS (-Table 4). Older age and oral contraceptives were negatively associated with good PCOS knowledge, 0.002 and 0.012 , respectively. However, married women $(p=0.001)$ and women with an increased level of physical activity $(p<0.001)$ or with undergraduate/postgraduate degrees $(p<0.001)$ tend to have better PCOS knowledge.

\section{Discussion}

Studies conducted in the middle east have reported a PCOS prevalence rate of 6 to $16 \%{ }^{21}$ Given the high prevalence of the disease and the broad range of metabolic, reproductive, and psychological issues that it may precipitate, it was cardinal to study the public's relative knowledge of PCOS and their perception of this syndrome.

As observed, women incorporated in this study reported considerably varying degrees of knowledge of PCOS. Twenty percent had inadequate knowledge (0-9), 36.4\% had satisfactory knowledge (10-17), and $43.6 \%$ had good knowledge (18-24). The mean knowledge score was determined to be $15.44 \pm 7.26$ and was graded as satisfactory. A significantly higher percentage of well-aware women was documented compared with other studies, which only compromised a limited percentage (21\%) of participants having good knowledge. $^{9}$ Thus, many participants were missing some vital details. Women in this study demonstrated good knowledge of the pathophysiology and management but lacked understanding of the physiology and complications. A patient's engagement in all disease aspects is undoubtedly indispensable for a successful treatment plan. ${ }^{19,22}$ Individuals would also improve their attitude toward the disease and minimize concern about possible complications once they acknowledge them. ${ }^{19}$

Most participants (85.3\%) in this study knew that diet and exercise could influence PCOS by decreasing the risk of

Table 4 Factors associated with participants' knowledge about PCOS

\begin{tabular}{|c|c|c|}
\hline Variable & $\begin{array}{l}\beta \\
\text { (95.0\% confidence } \\
\text { interval) }\end{array}$ & $p$-Value \\
\hline \multicolumn{3}{|l|}{ Age } \\
\hline$<25$ years & - & \\
\hline$\geq 25$ years & $-147(-3.488,-0.777)$ & $0.002^{*}$ \\
\hline \multicolumn{3}{|l|}{ Marital status } \\
\hline Single & - & \\
\hline Married & $0.553(6.844,11.031)$ & $0.001^{*}$ \\
\hline \multicolumn{3}{|l|}{ Educational level } \\
\hline Secondary & - & \\
\hline $\begin{array}{l}\text { Undergraduate/ } \\
\text { postgraduate }\end{array}$ & $0.583(9.087,11.797)$ & $0.001^{*}$ \\
\hline \multicolumn{3}{|l|}{ Employment status } \\
\hline Not working & - & \\
\hline Working (FT/PT) & $0.074(0.027,2.208)$ & $0.045^{*}$ \\
\hline \multicolumn{3}{|l|}{ Physical activity } \\
\hline Seldom & - & \\
\hline Occasionally/often & $0.140(1.079,3.230)$ & $0.001^{*}$ \\
\hline \multicolumn{3}{|l|}{ Smoking status } \\
\hline Non-smoker & - & \\
\hline Smoker & $0.094(0.173,2.897)$ & $0.027^{*}$ \\
\hline $\begin{array}{l}\text { Having chronic medical } \\
\text { conditions }\end{array}$ & $-0.021(-1.678,0.972)$ & 0.601 \\
\hline $\begin{array}{l}\text { Having a history of } \\
\text { infertility }\end{array}$ & $-0.017(-0.559,0.336)$ & 0.624 \\
\hline Using oral contraceptives & $-0.104(-1.613,-0.204)$ & 0.012 \\
\hline
\end{tabular}


having metabolic syndrome. Contrarily, a lower percentage (64\%) of respondents in other studies were aware that diet modifications could help with PCOS symptoms. ${ }^{9}$ Oxidative metabolism in tissues, including ovaries, is induced by physical exercises. This stimulation ultimately results in enhanced follicular growth and ovulation. ${ }^{9}$ Most of all, adopting a healthier lifestyle through diet and regular exercise protects against major metabolic diseases and other psychological events.

The most recognized PCOS features were the androgenrelated adverse effects (75.8\%), followed by the irregularity of menses $(72.7 \%)$ that was better noticed in the Jordanian study (90.3\%). ${ }^{17}$ In particular, women must be aware of the syndrome's features to relate to the disease and seek further investigations if they occur. In addition, more Lebanese women, around two-thirds, compared with Jordanian women, were aware of the different diagnostic criteria, who mostly knew about the ultrasound (66.5\%) and not blood test diagnosis (33.5\%). ${ }^{17}$ Lastly, women responding to queries about PCOS management had varying degrees of knowledge of different questions. Almost two-thirds of participating women were aware of the contribution of metformin, diet, and exercise in refining the progress of the disease. Adopting any of these three measures can result in decreased BMI and restored insulin sensitivity. ${ }^{4}$ Similarly, $80.6 \%$ of participants from another study knew that PCOS greatly benefits from reduced weight. ${ }^{17}$ While such a decrease in weight can alone restore the menstrual cycle to its regular rhythm naturally, this strategy cannot be suggested in non-obese or minimally overweight women because of limited data on the role of diet and exercise in this population. ${ }^{4}$

As for the participant's perception of the disease, most women agreed that PCOS requires social support and that most women with PCOS have a poor body image. Women also believed that PCOS naming is confusing and may not define the syndrome, similar to the study's findings conducted by Teede et al. ${ }^{22}$ To a lesser extent, participants also agreed that hirsutism associated with PCOS could be socially intimidating. Hirsutism has been noted to have a pronounced negative impact on health-related quality of life, where social support can be of particular help in this regard. ${ }^{23}$ In contrast, only an estimated half of the participants agreed that PCOS is a permanent disease that cannot be cured. Literature-based evidence builds upon these beliefs where a broad range of hampering psychological effects are affiliated with PCOS. ${ }^{13}$ Lastly, there was no clear consensus among women sharing in this study about the impact of PCOS on fertility. It is noteworthy that the new guidelines suggest that PCOS may result in infertility only in the case of oligo-ovulation or anovulation. ${ }^{4}$ In these cases, women may also benefit from an extended reproductive period due to increased ovarian reserve near menopause. ${ }^{4}$

Overall, married women were found to be more knowledgeable of PCOS, similar to the finding of other studies. ${ }^{17}$ This may be explained by the fact that married women may attend more meetings with gynecologists and be more likely involved in conversations about reproductive issues than unmarried women. However, those visits did not boost unmarried females' sexual and reproductive health knowledge, according to a study conducted by Hamdaniah et al. ${ }^{24}$ In addition, women with higher educational levels had a greater degree of knowledge, similar to what was observed in other studies. ${ }^{17,25}$

This is the first research study to estimate Lebanese women's knowledge and perception toward PCOS that enrolled subjects representative of the general population. Nevertheless, a significant limitation of this study is that the questionnaires were filled online without an inspector's observation. This may have increased the odds of miscomprehension of some questions. Also, participation in this study was voluntary, and it is possible that more confident and knowledgeable women were more eager to participate. Some women may not have had access to the internet, which limits the generalizability of the results. In addition, the research did not take into account the educational specialization of the participants.

\section{Conclusion}

According to the findings of this study, a significant percentage of Lebanese women have inadequate knowledge of PCOS and its complications. Women who were married and had a higher educational level had more knowledge about PCOS. Thus, improving women's knowledge regarding PCOS through public health awareness campaigns and support groups that target patients affected by PCOS is crucial to avoid unnecessary complications imposing heavy financial burdens.

\section{Authors' Contributions}

F.A. collected the data. F.A. and B.C. analyzed the data and were involved in writing and reviewing the final version of the manuscript.

\section{Ethics Approval}

Ethical approval was obtained for the study.

\section{Availability of Data and Material}

The datasets generated during and/or analyzed during the current study are available from the corresponding author on reasonable request.

\section{Conflict of Interest}

None declared.

\section{References}

1 Bozdag G, Mumusoglu S, Zengin D, Karabulut E, Yildiz BO. The prevalence and phenotypic features of polycystic ovary syndrome: a systematic review and meta-analysis. Hum Reprod 2016;31(12):2841-2855

2 Azziz R. PCOS: a diagnostic challenge. Reprod Biomed Online 2004;8(06):644-648

3 Strowitzki T, Capp E, von Eye Corleta H. The degree of cycle irregularity correlates with the grade of endocrine and metabolic disorders in PCOS patients. Eur J Obstet Gynecol Reprod Biol 2010; 149(02):178-181 
4 Orio F, Palomba S. Reproductive endocrinology: new guidelines for the diagnosis and treatment of PCOS. Nat Rev Endocrinol 2014; 10(03):130-132

5 Das M, Djahanbakhch O, Hacihanefioglu B, et al. Granulosa cell survival and proliferation are altered in polycystic ovary syndrome. J Clin Endocrinol Metab 2008;93(03):881-887

6 Nelson VL, Legro RS, Strauss JF III, McAllister JM. Augmented androgen production is a stable steroidogenic phenotype of propagated theca cells from polycystic ovaries. Mol Endocrinol 1999;13(06):946-957

7 Chen ZJ, Zhao H, He L, et al. Genome-wide association study identifies susceptibility loci for polycystic ovary syndrome on chromosome 2p16.3, 2p21 and 9q33.3. Nat Genet 2011;43(01): 55-59

8 Dallel M, Douma Z, Finan RR, et al. Contrasting association of Leptin receptor polymorphisms and haplotypes with polycystic ovary syndrome in Bahraini and Tunisian women: a case-control study. Biosci Rep 2021;41(01):BSR20202726

9 Pitchai P, Sreeraj SR, Anil PR. Awareness of lifestyle modification in females diagnosed with polycystic ovarian syndrome in India: explorative study. Int J Reprod Contracept Obstet Gynecol 2016;5 (02):470-476

10 Ding T, Hardiman PJ, Petersen I, Baio G. Incidence and prevalence of diabetes and cost of illness analysis of polycystic ovary syndrome: a Bayesian modelling study. Hum Reprod 2018;33(07): 1299-1306

11 Azziz R, Marin C, Hoq L, Badamgarav E, Song P. Health care-related economic burden of the polycystic ovary syndrome during the reproductive life span. J Clin Endocrinol Metab 2005;90(08):4650-4658

12 Hart R, Doherty DA, Mori T, et al. Extent of metabolic risk in adolescent girls with features of polycystic ovary syndrome. Fertil Steril 2011;95(07):2347-2353, 2353.e1

13 Månsson M, Holte J, Landin-Wilhelmsen K, Dahlgren E, Johansson A, Landén M. Women with polycystic ovary syndrome are often depressed or anxious-a case control study. Psychoneuroendocrinology 2008;33(08):1132-1138

14 Patel J, Rai S. Polycystic ovarian syndrome (PCOS) awareness among young women of central India. Int J Reprod Contracept Obstet Gynecol 2018;7(10):3960-3964

15 Haq N, Khan Z, Riaz S, Nasim A, Shahwani R, Tahir M. Prevalence and knowledge of polycystic ovary syndrome (PCOS) among female science students of different public universities of Quetta, Pakistan. Imperial J Interdisciplin Res 2017;3(06): 385-392

16 AlSinan A, Shaman AA. A study to measure the health awareness of polycystic ovarian syndrome in Saudi Arabia. GJHS 2017;9(08): 130-138

17 Abu-Taha M, Daghash A, Daghash R, Abu Farha R. Evaluation of women knowledge and perception about polycystic ovary syndrome and its management in Jordan: a survey-based study. Int J Clin Pract 2020;74(10):e13552

18 Avery JC, Braunack-Mayer AJ. The information needs of women diagnosed with Polycystic Ovarian Syndrome-implications for treatment and health outcomes. BMC Womens Health 2007; $7: 9$

19 Colwell K, Lujan ME, Lawson KL, Pierson RA, Chizen DR. Women's perceptions of polycystic ovary syndrome following participation in a clinical research study: implications for knowledge, feelings, and daily health practices. J Obstet Gynaecol Can 2010;32(05): 453-459

20 Ryan H, Trosclair A, Gfroerer J. Adult current smoking: differences in definitions and prevalence estimates-NHIS and NSDUH, 2008.J Environ Public Health 2012;2012:918368

21 Ding T, Hardiman PJ, Petersen I, Wang FF, Qu F, Baio G. The prevalence of polycystic ovary syndrome in reproductive-aged women of different ethnicity: a systematic review and metaanalysis. Oncotarget 2017;8(56):96351-96358

22 Teede H, Deeks A, Moran L. Polycystic ovary syndrome: a complex condition with psychological, reproductive and metabolic manifestations that impacts on health across the lifespan. BMC Med 2010;8:41

23 Ekbäck MP, Lindberg M, Benzein E, Årestedt K. Social support: an important factor for quality of life in women with hirsutism. Health Qual Life Outcomes 2014;12:183

24 Hamdanieh M, Ftouni L, Al Jardali B, et al. Assessment of sexual and reproductive health knowledge and awareness among single unmarried women living in Lebanon: a cross-sectional study. Reprod Health 2021;18(01):24. Doi: 10.1186/s12978-02101079-x

25 Alessa A, Aleid D, Almutairi S, et al. Awareness of polycystic ovarian syndrome among Saudi females. Int J Med Sci Public Health 2017;6(06):1013-1019 